
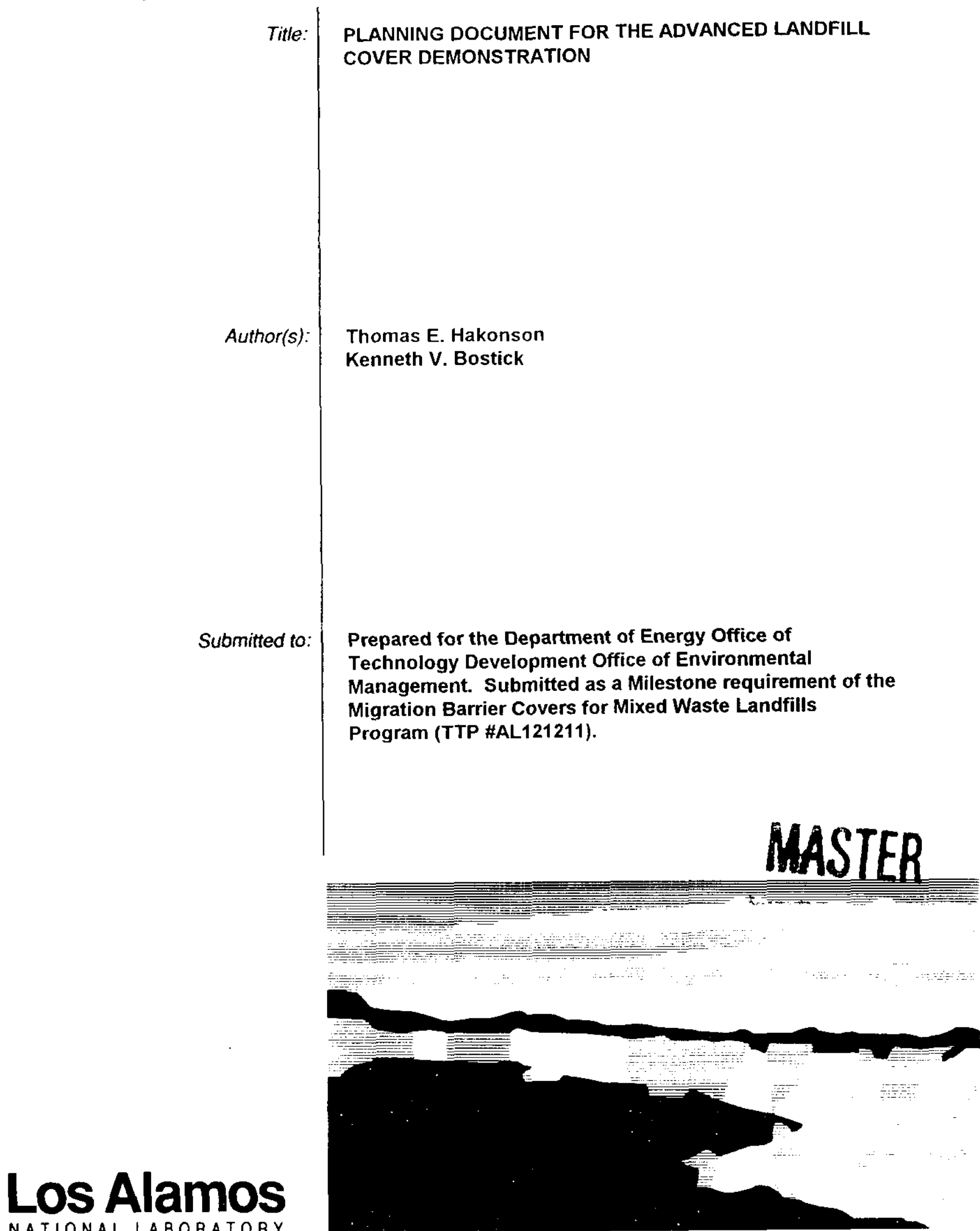

Los Alamos National Laboratory, an atfirmative action/equal opportunity employer, is operated by the University of California for the U.S. Department of Energy under contract W-7405.ENG-36. By acceptance of this article, the publisher recognizes that the US. Government retains a nonexciusive, royalty-free license to publish or reproduce the published form of this contribution, or to allow others to do so, for U.S. Government purposes. The Los Alamos National Laboratory requests that the publisher identify this article as work pertormed under the auspices of ine U.S. Department of Energy 


\title{
PLANNING DOCUMENT FOR THE ADVANCED LANDFILL COVER DEMONSTRATION
}

\author{
Thomas E. Hakonson \\ Center for Ecological Risk Assessment \& Management \\ College of Natural Resources \\ Colorado State University \\ Ft. Collins, Colorado 80523 \\ Kenneth V. Bostick \\ Environmental Science Group \\ Los Alamos National Laboratory \\ Los Alamos, New Mexico 87544 \\ Prepared for the Department of Energy Office of Technology Development Office of \\ Environmental Management. Submitted as a Milestone requirment of the Migration
} Barrier Covers for Mixed Waste Landfills Program (TTP \# AL 121211).

\section{DISCLAIMER}

This report was prepared as an account of work sponsored by an agency of the United States Government. Neither the United States Government nor any agency thereof, nor any of their employees, makes any warranty, express or implied, or assumes any legal liability or responsibility for the accuracy, completeness, or usefulness of any information, apparatus, product, or process disclosed, or represents that its use would not infringe privately owned rights. Reference herein to any specific commercial product, process, or service by trade name, trademark, manufacturer, or otherwise does not necessarily constitute or imply its endorsement, recommanufacturer, or otherwise does not necessarily Constitute or imply agency thereof. The views and opinions of authors expressed herein do not necessarily state or reflect those of the United States Government or any agency thereof. 


\section{PLANNING DOCUMENT FOR THE ADVANCED LANDFILL COVER DEMONSTRATION}

\section{INTRODUCTION}

The Department of Energy and Department of Defense are faced with the closure of thousands of decommissioned radioactive, hazardous, and mixed waste landfills as a part of ongoing Environmental Restoration activities. Regulations on the closure of hazardous and radioactive waste landfills require the construction of a "low-permeability" cover over the unit to limit the migration of liquids into the underlying waste. These landfills must be maintained and monitored for 30 years to ensure that hazardous materials are not migrating from the landfill.

In addition, there are innumerable private, municipal, State and Federal sanitary landfill sites as well as surface impoundments and mine and mill tailings piles which must conform to regulatory requirements for closure under EPA, DOE, or NRC guidelines.

Recently enacted Subtitle D RCRA regulations require solid waste landfills to be closed with engineered covers that meet the following performance objectives:

(1) cover permeability $\leq$ permeability of bottom liner/subsoil or no greater than $10^{-5} \mathrm{~cm} / \mathrm{sec}$

(2) minimizes infiltration with minimum of $18^{\prime \prime}$ soil

(3) minimizes erosion with at leasi 6" soil for plant growth

It is important to note that Subtitle D sets forth performance standards and nowhere specifies the cover design that must be used to comply with these standards. Subtitle D also allows the Director of an EPA approved State to consider and approve an alternative final cover design as long as it meets these general performance standards. 
EPA technical guidance (EPA, 1989) offers a design (referred to herein as the conventional cover design) for the closure of hazardous waste landfills. The convention cover design was developed principally for humid regions of the United States. and features a low conductivity soil (clay) hydraulic barrier to control the amount of water that percolates into the waste. As operating experience has been gained with compacted soil hydraulic barriers, shortcomings have become evident (Suter et al. 1993). Freeze-thaw, shrinkswell, erosion, subsidence, and plant and animal intrusion are processes that have been shown to negatively impact such layers. Desiccation, which can occur by several mechanisms, is an important failure mode for compacted soil hydraulic barriers, especially in arid environments (Suter et al, 1993).

Because of increasing evidence of the problems with clay hydraulic barriers, EPA is moving towards a greater reliance on a synthetic geomembrane that is placed over the hydraulic barrier to limit downward water movement. Geomembranes, which are typically constructed of polyethylene, can develop flaws such as tears, punctures, and open seams, during construction. They also do not accommodate large amounts of settlement and subsidence beneath them and they may degrade with time.

In addition to questions about the long term performance of the EPA recommended cover, the design is relatively expensive to install. The very large number of sites that require closure suggest that less costly designs, which still meet performance standards, will have a very large, beneficial economic impact on site cleanup efforts.

In conclusion, the need for field tested alternative cover technologies and associated monitoring systems is both apparent and immediate. DOE National Laboratory and DOD military base environmental restoration programs are actively using capping technologies for closure of landfills. All of these technologies, including the widely used RCRA cap (EPA, 1989) have had only limited technical evaluation under field conditions. While costs for different capping technologies can vary by 1-2 orders of magnitude, they can be equally effective in meeting mandated performance objectives. Consequently, field tested cover alternatives are needed to help the risk manager select technologies that are both technically appropriate and cost effective.

In response to that need, National Laboratory, EPA, Corps of Engineers, USDA, university, and industrial partners, collaborating under the Mixed Waste Landfill Integrated Demonstration (MWLID), will design, construct, and fully monitor several advanced landfill 
cover alternatives and compare their technical performance with respect to regulatory performance standards and cost.

\section{PURPOSE OF TEST PLAN}

This test plan is intended as an initial road map for planning, designing, constructing, evaluating, and documenting the Advanced Landfill Cover Demonstration (ALCD). It describes the goals/objectives, scope, tasks, responsibilities, technical approach, and deliverables for the demonstration. The plan is a living document whose content will change as the various phases of the demonstration evolve. Detailed equipment and procedural plans will be prepared as necessary as the planning for the ALCD evolves. All phases of the ALCD will conform to the QAVC requirements specified in the MWLID Quality Assurance Project Plan (AL-2211-12-01, 1992).

\section{GOALS AND OBJECTIVES}

The goal of the Advanced Landfill Cover Demonstration is to:

field test, compare and document the performance of alternative landfill cover technologies, of various complexities and costs, for interim stabilization and/or final closure of landfills in semi-arid environments.

The objectives are to:

1) demonstrate the constructability and costs of cover design alternatives,

2) measure the performance of the design alternatives over a 3-5 year period using water balance and ancillary data as the primary evaluation method,

3) validate predictive models and decision tools for evaluating longterm performance of the cover designs, and 
4) document the constructibility, technical performance, and cost of the ALCD cover alternatives through presentations, reports, and peer- reviewed publications.

\section{SCOPE OF THE ALCD}

The Department of Energy, Office of Technology Development has supported a variety of related efforts to develop landfill cover systems and associated monitoring technology as a part of the Mixed Waste Landfill Integrated Demonstration at Sandia National Laboratory (SNL) in Albuquerque New Mexico. Development projects that the MWLID has funded include:

- Migration Barrier Covers for Mixed Waste Landfills (TTP\# 121211)

- Prototype Decision Support System for Evaluating Landfill Covers (TTP\# 131001)

- Post-closure Monitoring for Mixed Waste Landfills (TTP\# 141004), and

- Dry Barriers for Mixed Waste Landfills (TTP\# AL 231002),

The goal of the development program was to, 1) collect fundamental data on measuring, modeling, and evaluating landfill cover performance, based on both laboratory and small scale field experiments, at a variety of locations in the United States and, 2) to integrate the knowledge and data from those studies into designing, constructing, and monitoring several advanced landfill cover alternatives at Sandia National Laboratory's mixed waste landfill in Albuquerque, New Mexico.

The ALCD will evaluate replicates of 5 landfill cover designs (10 plots total), representing a range of complexities and installation costs. Two of the cover designs (one with compacted clay barrier and one with a clay geosynthetic barrier) will represent the EPA recommended design as stipulated in the latest guidance documents; these are the cover designs an environmental engineering firm would likely use to remediate a landfill.

Two capiliary barrier designs will be tested against the EPA's conventional design. The first is a state-of-the-art capillary barrier design developed from extensive investigation at Los Alamos. This design emphasizes plants as a means of controlling soil moisture (via 
evapotranspiration) and an optimized capillary barrier to limit water from percolating through the cover. Variations of this design have been investigated extensively by Los Alamos over the last 12 years including features to control animal and plant intrusion through the cover and to maximize evapotranspiration using optimized vegetation cover.

The second capillary design incorporates the dry barrier concept being developed by the University of New Mexico (UNM), D. B. Stephens \& Associates (DBS\&A), and Sandia National Laboratories. This concept uses air flow through a capillary barrier to remove moisture, and hence improve the performance of the capillary barrier design in limiting percolation of water through the cover. During the past two years, the dry barrier concept has been evaluated in modeling, laboratory, and small-scale field studies at Sandia National Laboratories. These studies have demonstrated the validity of the dry barrier concept and found that passive systems, using wind-powered turbine vents, can induce sufficient air flow within porous layers of a landfill cover to remove a large percentage of the annual precipitation.

The final design consists of a vegetated soil cover that represents past practice in closing a landfill. This design is necessary to serve as a baseline for comparing the performance of the other designs and to validate the baseline case for the Decision Support System.

The Decision Support System (DSS) for evaluating landfill cover designs will be used to the extent possible to develop specifications for the different covers. The DSS system is being developed by the U.S. Department of Agriculture (TTP\# 131001) and utilizes decision theory to optimize the various landfill cover system components based on criteria such as allowable percolation, desired run-off and cost. The DSS has evolved from an expert system developed by The U.S. Department of Agriculture-Agricultural Research Service (USDA-ARS) to evaluate the impact of agricultural practices on water quality to be assessed (Stone et. al, 1993). The EPA's HELP (Hydrologic Evaluation of Landfill Performance) model, which is embedded in the DSS, is being modified to simulate capillary barriers as well as compacted soil hydraulic barriers. The US Corps of Engineers, under EPA sponsorship, have collaborated in the USDA's modifications to HELP.

Instruments will be installed to measure runoff and erosion, change in soil moisture storage, percolation through the cap, and lateral flow from those designs with clay, capillary, or dry barriers. Evapotranspiration will be estimated by solving the water balance equation. Meteorological measurements will include precipitation, wind speed, humidity 
and barometric pressure. Monitoring will commence upon completion of the construction phase and continue for at least 3 years.

Natural precipitation will drive the hydrologic response of the various cover designs. Supplemental precipitation may also be applied to half of the plots after the first year to hydrologically stress the cover design components.

\section{TASKS}

This test plan elaborates on 5 Tasks that must be accomplished in order to achieve the goal and objectives of the ALCD. Those tasks are:

\section{Task 1- Scoping the Study}

- Coordinate with SNL ER, NMED, and EPA to scope on-site and applicable regulatory requirements for the study

- Prepare H\&S plan, SOP's and other documentation as needed

\section{Task 2- Site Selection and Characterization}

- Coordinate with SNL in selecting a location for the study

- Characterize the near field area including major faunal and floral association, geology, hydrology, and climate. Most of this information will come from existing SNL and/or UNM documents. Some additional characterization of vegetation and soils may be required in the immediate area of the study location.

- Conduct DSS analysis of candidate cover designs

Task 3- Construction of Test Plots

- Identify local vendors and establish contracts

- Assemble materials and equipment 
- Construct test plots and irstall instrumentation

\section{Task 4- Monitor Test Plots}

- Collect data on precipitation, runoff and erosion, infiltration, soil moisture, and percolation from the bottom of each cap design as a function of time. We will attempt to use automated data acquisition systems for most of the measurement variables

- Periodically measure characteristics of the vegetation cover on each plot

- Manage computer data base

Task 5- Documentation of Cap Design Performance

- Summarize, compare, and document water balance data for cover designs to quantify potential benefits of the alternative designs,

- Compare and document DSS predicted performance with field data to evaluate merits of DSS, and

- Document recommendations on use of cover alternatives for interim stabilization and/or closure of landfills in semi-arid sites.

\section{RESPONSIBILITIES}

Overall responsibility for the ALCD lies with the MWLID project officer at SNL. Designees for lead role will be responsible for completion of the task with assistance from other collaborators as needed. Co-lead responsibilities will require active participation in accomplishing the task/s while input/review responsibilities provide data and/or comment to lead and co-lead collaborators.

We visualize the active participation of graduate students from Colorado State University (CSU) and UNM in monitoring, evaluating, and documenting study results. Project principals will serve as mentors, thesis committee members, and/or thesis advisors. 


\section{TECHNICAL APPRQACH}

\section{TASK 1-SCOPING}

\section{OBJECTIVES/SUBTASKS:}

1. Gain input and philosophical approval of NMED and EPA, Region 6, for the ALCD cover designs,

2. Establish a peer review panel to help guide the ALCD, and

3. Secure administrative approval for the ALCD by submitting necessary permits and $H \& S$ documents.

Deliverable: Appropriate H\&S plan/s, SOP's, and other documentation as necessary.

Subtask 1- A key ingredient to the effective transfer of remediation technology to user organizations is buy-in by the cogent regulatory authority/ies. We will make a concerted effort to gain, at least philosophical approval by NMED and EPA, Region 6 for the demonstration and, especially, for the cover designs being evaluated. Regulatory concerns about candidate cover designs for the ALCD will be addressed, in so far as possible, before the final designs are selected. Important components of this subtask are to:

- $\quad$ select cover designs,

- prepare briefing materials,

- contact cogent agency personnel,

- conduct briefings, and

- attempt to get written support from the agency.

Sandia National Laboratories will have lead responsibility for this task with assistance from other participants as requested. 
Subtask 2.- A peer review panel will also be established to evaluate the quality and direction of the ALCD. Members for the panel will be selected from university, National Laboratory, regulatory, and private industry organizations to represent a mix of technical and user interests. Important components of the subtask include:

- input from ALCD participants for recommendations,

- input from SNL program managers,

- input from DOE, and EPA for candidate panel members,

- decide on role of panel,

- possible fee for service,

- meeting frequency,

- $\quad$ product from panel, and use of product.

Sandia National Laboratories will lead in this subtask with input from other participants. A peer review panel should be selected and subjected to an initial briefing by October 1 , 1994.

Subtask 3- Securing permits and satisfying applicable H\&S requirements are important tasks that must be addressed very early in the ALCD. The compliance and environmental restoration groups at SNL, the NMED, and EPA, Region 6, all need to be apprised of the ALCD to identify ARAR's that could impact on the conduct of the demonstration. Important components of this subtask include:

- generating list of security, $\mathrm{H} \& \mathrm{~S}$, environmental issues that might require permits/approvals,

- identify cogent compliance groups and personnel,

- $\quad$ prepare response to requirements, and

- get documentation of ALCD compliance with ARAR's.

- $\quad$ QAVC requirements and oversight

Sandia National Laboratories will lead this subtask. The ARAR's applicable to the ALCD should be identified by October 1, 1994 and a response plan approved by January 1, 1995. Special concerns include the potential release of liquids (NPDES)collected as runoff and/or leachate and radiological safety safe issues (transport and personnel exposures) associated with using the neutron moisture gage. 


\section{TASK 2- SITE SELECTION/CHARACTERIZATION}

\section{OBJECTIVES/SUBTASKS}

1.- Select a site that is compatible with the goals of the ALCD,

2.- Collect and review all pertinent physical, biological, and chemical data for the site for use in designing and modeling candidate cover designs, and

3.- Conduct hydrologic analysis of candidate cover designs with DSS

Deliverable: A summary of available information will be presented in report describing the results of the DSS evaluation of candidate cover designs.

Subtask 1- A site of about 1 ha (2.5 acres)extent will be selected for the ALCD, preferably in an area where excavated soils can be used in constructing portions of all cover designs. The location will be in a "clean" area to avoid special permitting and $H \& S$ concerns associated with using an actual waste site. The site should have electrical power to facilitate use of automated data acquisition systems. Fencing should be considered to control access to the site. Important components of this subtask include:

- deciding on exact land area requirements,

- time land needed for study,

- facility/service/security needs,

- access requirements (i.e. for students),

- identify SNL facilities control personnel,

- brief facilities control personnel on needs,

- get written approval for use of site and necessary services.

Sandia National Laboratories will lead this subtask.

Subtask 2- All available data on the physical, biological, and chemical characteristics of the site, or a surrogate site, will be assembled to assist in the development of final cover designs for the ALCD using the DSS. Data requirements for initializing the HELP model 
embedded in the DSS are particularly important to improve the evaluation of the candidate cover designs. Some of the information needs include a variety of geotechnical and hydrologic properties of soil, including grain size, porosity, and saturated conductivity, climate, including mean monthly temperatures, wind speed and direction, daily precipitation, in the form of rain and snow, relative humidity, water balance relationships, and native vegetation communities, including rates of recovery/succession. Additional laboratory and field tests may be necessary to fill critical information gaps. Important components of this subtask include:

- identifying sources of data including SNL surveillance, ER, and research groups, UNM, US Department of Agriculture-Soil Conservation Service (USDA-SCS), US Bureau of Mines (BOM), NM Institute of Mining and Technology (NMIMT), NM State University (NMSU), and NM State Land Office,

- generating list of data/information needs,

- conducting records/literature search,

- summarizing data,

- $\quad$ preparing report, and

- disseminating information to cogent collaborators.

Sandia National Laboratories will lead this subtask with major assistance from DBS\&A, USDA-ARS and CSU. DBS\&A will develop information needs relative to the Dry barrier technology and USDA-ARS will prepare a list of data needs required to run the DSS. CSU will develop an analogous list of information needs for designing the vegetation cover on each plot. This subtask should start by June 1, 1994 and be completed by August 1, 1994.

Subtask 3- The DSS analysis will evaluate several modifications of each candidate cover design to determine optimum configuration for a particular design. For example, surface slope will be varied to determine the optimum for enhancing runoff while keeping erosion within EPA limits of $4.4 T /$ ha. Likewise, thicknesses of the various layers will be evaluated to determine the optimum needed for soil water storage. Barrier features can also be examined including slope and slope length. Important components of this subtask include:

- selecting collaborator contacts to interact with DSS team,

- selecting candidate cover designs,

- identifying design constraints,

- developing initializing data and information for the DSS, 
- identify specific product desired from the DSS analysis,

- $\quad$ preparation of report on DSS analysis of candidate designs, and

- recommendations.

The USDA-ARS will lead this effort with input from the other participants.

\section{TASK 3- IMPLEMENTATION}

\section{OBJECTIVES/SUBTASKS}

1. Select, design, and develop drawings for cover alternatives,

2. Select and design monitoring system, and

\section{Construct ALCD.}

Deliverable: Letter report and photos/slides to Project Officer documenting completion of construction phase

Subtask 1- Based on the DSS analysis, a review of literature, and input from State, EPA, and DOE stakeholders, the cover designs will be finalized and documented. A report will be prepared from participant input on the materials, equipment, QAQC, and services requirements for each cover design. Engineering drawings and construction specifications will be prepared including estimated costs of materials and services by cover alternative. Important components of this subtask include:

- selecting the number of designs to install,

- exact dimensions of the plots,

- selecting the exact configuration for each design including the vegetation cover, erosion control practice, surface slope, profile thicknesses, design of barrier interfaces (i.e. geotextiles?), barrier slopes and slope lengths,

- Prepare a detailed description of each design,

- Prepare materials and equipment needs,

- Acquire all materials and equipment,

- geotechnical properties, compaction requirements, QAVC requirements for soils/barriers, 
- $\quad$ selecting AE firm to generate drawings and provide cost estimates,

- report on final designs and selection criteria, and

- report on materials and services (M\&S), equipment, and QAQC requirements for ALCD

Sandia National Laboratories will lead this subtask and will delegate responsibilities to coleads as necessary. While work is already underway on several elements of this subtask, it will be necessary to agree on the designs and develop final configurations before final M\&S, etc lists and drawings can be prepared.

Subtask 2- The success of the ALCD will depend heavily on the quality of the monitoring systems and the care taken in their installation and follow-on maintenance. The monitoring equipment will be designed for measuring most of the components of water balance and additional ancillary variables. We intend to couple the DAS to a phone line so that remote interrogation of the monitoring system is possible.

A simplified representation of water balance describes surface runoff and one-dimensional movement of water in the soil profile to the plant rooting depth. For net rates and amounts in units of $\mathrm{cm}$, the water balance equation is:

$$
d S / d t=(P-Q-E T-1-L) / d t
$$

where $d S / d t$ is the time rate of change in soil moisture storage, $P$ is the precipitation, $Q$ is the runoff , ET is the evapotranspiration , $l$ is the lateral flow from hydrologic barriers in the profile, $L$ is the percolation below the root zone, and $t$ is the unit of time used in solving the equation. , With the exception of ET, estimates of all terms in Equation 1 will be obtained with the monitoring systems. Evapotranspiration will be estimated by solving Equation 1 for ET. Other measurement variables include erosion, precipitation, relative humidity, barometric pressure, soil temperature with depth, vegetation biomass and cover, and wind speed and direction. Most of the physical attributes will be measured with automated monitoring systems to provide continuous data. Characteristic of the vegetation will be measured seasonally.

SOIL MOISTURE. Time Domain Reflectrometry (TDR) and an associated data acquisition system will be used to provide a continuous record of soil moisture status at various depths in each cover profile. Results of on-going studies will be analyzed to help design the spatial arrangement of the monitoring equipment. Important components of this activity include:

- Solicitation of collaborators for spatial and temporal soil moisture monitoring needs (QAQC requirements), 
- Analysis of Los Alamos and other TDR studies to evaluate spatial variability,

- Determine number of TDR's needed, power requirements, and procure equipment,

- Design TDR array for ALCD,

- Develop installation plan,

- $\quad$ Acquire data acquisition system (DAS), and

- $\quad$ Calibrate and bench test TDR's and DAS

- Develop data management and analysis system

Los Alamos will lead this effort with major contributions from SNL/DBS\&A.

RUNOFF AND EROSION. It is visualized that relatively few runoff events will occur during the course of the demonstration. However, runoff and erosion will be measured on an event basis. Depth measuring transducers and storage tanks with flush valve or self siphoning discharge systems will provide runoff event hydrographs. Sediment will be separated from runoff in a settling tank located downstream from the runoff measuring system to provide total soil loss for each runoff event. Important components of this activity include:

- $\quad$ Selecting the scale for monitoring runoff and erosion (i.e. whole plot vs subsample),

- Running CREAMS to scale the size of collector system to maximum probable runoff event,

- Assembling collectors, transducers, DAS,

- Developing installation plan

- $\quad$ setting up prototype and bench test the system, and

- developing data management and analysis system.

PERCOLATION AND INTERFLOW Subsurface flows will be measured using pan lysimeters, gutter drains, stilling wells, depth transducers, self siphoning discharge systems and a data acquisition system to continuously record flow events. A gutter drain will be used to intercept interflow from the various barriers. Percolation out of the cover designs will be measured with pan lysimeters located at several positions along the long axis of each plot. Both percolation and interflow will be routed via drains to the flow monitoring system. The monitoring system will consist of stilling wells, depth transducers, self siphoning discharge valves, and sump pumps. Measurement redundancy will be built into the system to reduce chances of losing data due to equipment failure or power losses. To avoid problems with inclement weather, the monitoring instrumentation will be housed in a 
shelter that may be above or below ground depending on whether the plots are constructed on- or below- grade. Important components of this activity include:

- Deciding on the scale of flow monitoring (i.e. whole plot vs subplot),

- Designing and fabricating pan lysimeters and gutter drains,

- Designing and acquiring components for flow monitoring system,

- Designing and acquiring components for data acquisition system,

- Developing installation plan,

- Designing flow monitoring shelter,

- Developing data management and analysis system,

Sandia National Laboratories, DBS\&A, and Los Alamos will share lead responsibilities for this activity.

\section{METEOROLOGY}

A complete National Weather Service met station will be installed at the ALCD site. Precipitation, air temperature, soil temperature, wind speed and direction, barometric pressure, relative humidity, and solar radiation will be continuously recorded. Additional measurements will made on snow depth with sonic transducers, accumulative precipitation with can type gages, and precipitation at ground level. Most of the meteorological measurements will be made with automated equipment coupled to a data acquisition system. The DAS will be housed in the percolation and interflow monitoring shelter. Important components of this activity include:

- Finalizing met data requirements based on participant input,

- Acquire all equipment,

- Establishing QAVQ requirements,

- Develop DAS system

- $\quad$ Finalizing measurement methods,

- Finalizing equipment locations,

- Calibrating and testing equipment,

- Develop data management and analysis system, and

- Decide on frequency of measurement and data analysis. 
Los Alamos, SNL, and DBS\&A will share lead responsibilities for this activity. The final met system should be assembled and tested by $4 / 95$.

\section{VEGETATION}

Attributes of the vegetation will be measured seasonally throughout the study to related to changes in erosion and evapotranspiration. A point frame will be used to evaluate cover and leaf area. Biomass will be determined by clipping and weighing oven dried samples collected from subplots within each cover design. Species composition will be measured using line transects and or quadrats. Important components of this activity include:

- Identifying attributes relative to assessing cover system performance,

- Decide on characterization methods, and

- Develop data management and analysis system.

CSU will lead this activity with major input from LANL and USDA-ARS. This activity will commence as soon as plot construction is completed.

Subtask 3- Once cover designs and monitoring systems have been finalized, a detailed construction plan that lists step by step procedures for building and instrumenting the ALCD will be prepared. An SNL project manager will oversee the acquisition, delivery, and installation of all materials, equipment, and services needed to construct the ALCD. A contractor will be hired to assist in the construction under the direction of the project manager and with input from the participants. Participants responsible for specific cover designs or monitoring systems should be on-site when needed to assist in the construction activities, validate the QA/QC requirements, conduct in-situ tests, and approve of the finished product. Records will be maintained to document construction problems and costs for each cover design.

In general, the procedural plan will consist of the following activities:

- Ensure that all necessary approvals are in place,

- Develop step by step construction plan,

- Develop plan for in-situ measurements required during construction, including soil moisture content, Proctor tests, hydraulic conductivities, etc. 
- Use engineering drawings and construction plan to write bid specs for acquiring a contractor to coristruct the ALCD,

- $\quad$ Acquire or have fabricated all materials and equipment not covered above including equipment shed, fencing, landscaping, soils/clay (Screened and pre-moistened), synthetic barrier materials, vegetation seeds/seedlings, gravel, base course, surface plot borders, side wall plot separators, instrument shelters, signs, and etc.

- Assemble all materials or arrange for their timely delivery according to the construction plan,

- Excavate plot area to depths dictated by respective cover designs, slope, and compact plot foundation,

- install side wall plot borders,

- $\quad$ place pan lysimeters on plot foundation and install drain piping,

- backfill lysimeters with gravel to promote free drainage of percolation,

- $\quad$ prepare soils for placement (i.e. optimum moisture content),

- $\quad$ place barrier layer of cover profile with material and compact to specs (i.e. Proctor tests, in-situ conductivities) as appropriate ,

- install interflow gutter drains and piping and other equipment (dry barrier piping),

- repeat for additional layers,

- install surface plot borders,

- install runoff gutter drains,

- excavate TDR installation trench,

- install TDR instrument package,

- excavate instrument/monitoring shelter,

- install power source and modem for data interrogation,

- install met station,

- run percolation and interflow drains, TDR cables, met station cables, and runoff flow gages to shelter,

- install flow measuring system and DAS,

- vegetate plots,

- develop final report on design details as actually constructed,

- landscape, post signs, and fence ALCD area,

- design and install PR exhibit.

- document construction problems by design, and

- document costs by design.

SNL will lead this subtask and delegate as necessary to distribute the work load. 


\section{TASK 4- PERFORMANCE MONITORING}

\section{OBJECTIVES/SUBTASKS:}

1. Collect continuous data on precipitation, runoff and erosion, infiltration, soil moisture, percolation from the bottom of each cap design, and ancillary supporting data for a 3-5 year post construction period.

2. Periodically measure characteristics of the vegetation cover on each plot

3. Manage computer data base

Deliverable: Annual report, interim reports, and photos/slides as necessary to Project Officer

Subtask 1- Passive Monitoring- All ALCD plots will be monitored for at least one year under ambient climatic conditions. For the first few months, daily on-site observations will be required to validate system performance and to correct problems. As the reliability of the system is established, less frequent on-site observations will be necessary. Continuous data will be obtained for soil moisture status, percolation and interflow, runoff and erosion, precipitation, wind speed and direction, relative humidity, barometric pressure, air and soil temperature, and snow depth. Periodic measurements will be obtained on vegetation cover, biomass, leaf area index, and species composition. Depending on the needed to supplement precipitation, all or at least half of the plots will be monitored for at least 3 years post-construction. It will take that long for the plots to develop a good vegetation cover.

Active Monitoring-_Supplemental precipitation may be added in the form of rain and/or snow to hydrologically stress the various barriers systems. Application of rain will use a sprinkler system tested for rate and uniformity of application. Snow would be applied with a snow making machine. Application rates for both forms of precipitation would probably be 2 or 3 times average annual values for Albuquerque, NM distributed daily or weekly. All other measurements under this precipitation regime would be the same as described above for passive monitoring. 
Important components of this subtask include:

- Specifying supplemental precipitation application rates,

- Develop a monitoring schedule for the various variable,

- assign responsibilities for on-site monitoring tasks,

- Develop uniform data recording forms compatible with data management program,

- Develop software and assign responsibility for data management and analysis,

- Develop QAVC procedures for verifying equipment calibrations and data accuracy, and

- meet periodically to review data and data quality.

SNL will lead this effort with major assistance from DBS\&A and LANL. Monitoring will commence upon completion of plot construction and continue for 3-5 years.

Subtask 2- Changes in the characteristics of the vegetation cover are needed to support modeling of evapotranspiration and to relate to seasonal changes in water balance and erosion. Quantitative data will be obtained on relative cover, species composition, and biomass. A photographic record will also be maintained. Important components of this subtask include:

- Develop vegetation characterization methods,

- Develop sampling schedule, and

- Develop data management and analysis system.

CSU will lead this effort.

Subtask 3- The data management and analysis software, SASS, will be used to store and manipulate ALCD monitoring data. Procedures will be developed to interrogate data loggers via phone line, down load DAS memory to a PC or workstation in SASS format, and automatically manıpulate raw data and update files. Routines will also be written to analyze and present the data in various output formats. A computer network link will be established between participants for updating and retrieving data files. Important components of this subtask include:

- Designating data management and analysis responsibilities,

- Developing participant hardware and software requirements, 
- Setting up software framework, analysis routines, and output options for monitoring data,

- Develop statistical design for significance tests,

- Develop network link between participants,

- Develop user interface with data base, and

- Document data base management, analysis options, and user interface procedures.

LANL, SNL, and DBS\&A will co-lead this activity with LANL providing an archive, analysis, and data output role, SNL providing overall requirements for the data base, and DBS\&A providing specific technical requirements for the data management system.

\section{TASK 5- RESULTS AND RECOMMENDATIONS}

\section{OBJECTIVES/SUBTASKS:}

- Summarize, compare, and document water balance data for cover designs to quantify potential benefits of the alternative designs,

- Compare and document DSS predicted performance with field data to evaluate merits of DSS, and

- Document recommendations on use of cover alternatives for interim stabilization and/or closure of landfills in semi-arid sites.

Deliverable: Final report, peer reviewed publications, and photos/ slides on results of study to Project Officer. Stand alone report on comparison of DSS results with field data.

Subtask 1- Hydrologic monitoring data will be used to compute a daily water balance (see Equation 1) for each cover design as a means of identifying which design/s best meet regulatory performance objectives (see Introduction). Analysis of Variance techniques will be used to test for statistical significance of differences in water balance components between designs and as a function of precipitation rates. Special emphasis will be placed on evaluating the barrier alternatives with emphasis on technical performance, constructability, and cost. Instrumentation installed as a part of the post-closure monitoring activities will also be evaluated relative to technical performance, deployability, and cost. Variables that will be quantitatively or qualitatively compared include: 
- runoff

- erosion,

- change in soil moisture,

- interflow or interflow plus water vapor removal,

- percolation,

- evapotranspiration,

- vegetation cover, biomass, and species composition,

- constructability, and

- cost

Important components of this subtask include:

- Generating final summary data in required format (i.e. had copy, disk, etc.),

- Computing daily water balance,

- Conducting statistical analysis, and

- Generating interim reports on results

SNL, DBS\&A, LANL, and CSU will share responsibilities for this subtask. Plans and mechanisms for dissemination of project activities should begin now.

Subtask 2- The DSS predicted performance of the ALCD cover designs will be compared with field data using regression and ANOVA techniques. Details for this comparison are presented in the DSS Design Document, LA-UR-94-570. Important components of this subtask include:

- Parameterizing the DSS with initializing data from the ALCD as built,

- Running the DSS for ALCD cover designs,

- Formatting monitoring data for comparison of DSS output,

- Conducting statistical tests for differences between DSS and field data,

- Documenting results of comparisons, and

- Future recommendations for the DSS.

USDA-ARS will lead this task with major input from LANL and CSU. 
Subtask 3- Aggressive plans for dissemination of ALCD activities include presentations at briefings, technical and operational meetings, and symposia, reports, peer reviewed publications, and books. Important components of this subtask include:

- Assigning publication/presentation responsibilities,

- Assign publication/presentations coordinator,

- Determine mechanisms for paying for publications (i.e. large \#s of reports),

- Preparing individual reports from participants,

- Integrating individual reports,

- Peer review of all reports,

- Identify publication vehicles, and

- Publish individual/integrated papers

SNL. will lead this subtask with major input from all participants.

\section{EXPECTED BENEFITS OF THE ALCD}

The outcome of this demonstration will be a critical evaluation of the various cover designs, and a recommendation for alternative cover designs for landfills in the western US. The intent is to widely publish and disseminate the data so as to bring the advantage/limitations of each of the designs to as many public, regulatory and design individuals as possible.

We expect the demonstration to provide performance and cost data for cover components and systems that are more applicable to western climatic conditions. A direct comparison between conventional (based on non-arid climates) and alternative designs will be available. The "active" testing will permit data to be collected under extreme and accelerated conditions. This information will allow those responsible for the development of landfill cover design guidance to have a defensible basis for the transition of designs from that based on the eastern US to those found in the western United States.

This demonstration project should help verify the use of the DSS for landfill cover design. The demonstrations will provide data from extreme conditions (arid and high-precipitation) which will be used to test the capabilities of the DSS. The DSS will be a powerful tool for applications at other sites. 
The probable outcome of this demonstration is the acceptance of alternative cover designs which are significantly less costly than the conventional design. Whereas the EPArecommended design can cost more than a million an acre, the alternative designs which utilize capillary barriers will be less than one-half the cost. Given the thousands of acres of buried waste sites to be covered, the pay off from this demonstration may be on the order of many millions of dollars in savings.

\section{MILESTONES}

1. Design of arid site demonstration

$09 / 94$

2. Construction of arid site demonstration

$06 / 95$

3. Complete active testing of arid and high-precipitation demos

$06 / 97$

4. Complete evaluation of arid and high-precipitation demos

$09 / 98$

\section{IRANSITION PLAN}

The EPA technical guidance permits alternative landfill cover designs that can be demonstrated to be equivalent in performance to the generic design. Recent design innovations indicate that new components and systems could become extremely effective for western landfill sites. For example, site-specific non-conventional designs which emphasize vegetation and capillary barriers are being demonstrated at LANL and PNL. Geosynthetic clay liners are being suggested as a replacement for compacted clay layers in cover systems by researchers at the Geosynthetic Research Institute and other EPAsponsored researchers. The key issue is that the alternative cover designs be satisfactorily demonstrated to permit the cost and performance advantages to be explicitly recognized. By benchmarking these demonstrations to the EPA-recommended design, the advantages and limitations will be unambiguous and more acceptable to the environmental restoration community.

The transfer of this technology to the user (geotechnical engineering consulting firms) will be enhanced because of the tremendous commercialization potential for the alternative landfill cover technology. Every hazardous and mixed waste landfill, and many solid waste landfills, will require closure with a cover system. Conventional covers do not perform well in the western US and are expensive, so alternatives which have been demonstrated to be as or more effective will be very appealing. 
The acceptability of the alternative landfill covers to the regulatory, site owner/operator, consulting engineer, and geotechnical construction companies will be motivated by the simplicity of these designs. The compacted soil layers featured in conventional designs are difficult to emplace to design specifications. The performance of geosynthetics used in conventional designs is dependent upon very careful installation and rigorous quality assurance. In contrast, the construction of alternative designs is more straightforward and less reliant upon the performance of the installation contractor.

\section{PARTICIPANTS}

The lead laboratory for this project is Sandia National Laboratories. Sandia will be responsible for the overall project. Los Alamos National Laboratory, with assistance from Colorado State University, will provide technical support for the design and evaluation of the demonstration. The US Department of Agriculture, Agricultural Research Station will be applying the Decision Support System to the design and evaluation of the various landfill cover designs. Robert Landreth of the EPA's Risk Reduction Engineering Laboratory (513-569-7871) has expressed a specific interest in this project, and recognizes the significance of this demonstration to the regulatory design guidance for landfill cover systems in the western US. Paul Schroeder of the US Army Corps of Engineers Waterways Experiment Station (601-634-3709) developed the HELP model for the EPA, and supports this demonstration as it will aid in the verification of the HELP model under conditions representative of the western US.

\section{ACKNOWLEDGMENTS}

This work was prepared for the Department of Energy Office of Technology Development Office of Environmental Management. This work is conducted in support of the Mixed Waste Landfill Integrated Demonstration at Sandia National Laboratory, Albuquerque, New Mexico. 